\section{SOI: 1.1 /TAS DOI: $10.15863 /$ TAS}

International Scientific Journal Theoretical \& Applied Science

p-ISSN: 2308-4944 (print) e-ISSN: 2409-0085 (online)

Year: 2015 Issue: 10 Volume: 30

Published: $30.10 .2015 \quad$ http://T-Science.org

SECTION 31. Economic research, finance, innovation, risk management.
Natalia Vladimirovna Batciun

Associate Professor,

Department of World Economy

Irkutsk National Research Technical University, Russia nbatsun@mail.ru

Dar'ya Vladimirovna Prosjanova Master,

Department of Mineral processing and engineering Ecology Irkutsk National Research Technical University, Russia lessa_d@mail.ru

\title{
ENVIRONMENTAL MANAGEMENT ECONOMY: THE SYSTEM OF STATE ADMINISTRATING ATHMOSPHERIC AIR PROTECTION AT THE REGIONAL LEVEL
}

Abstract: Main goal of business is receiving profit and methods on achievement of this purpose conflict to the main values of society. As a result - the market relations demand the corresponding regulation from the state.

Key words: the market relations, public administration, permission to emissions of the harmful (polluting) substances, payment for pollution of atmospheric air.

Language: Russian

Citation: Batciun NV, Prosjanova DV (2015) ENVIRONMENTAL MANAGEMENT ECONOMY: THE SYSTEM OF STATE ADMINISTRATING ATHMOSPHERIC AIR PROTECTION AT THE REGIONAL LEVEL. ISJ Theoretical \& Applied Science 10 (30): 100-104.

Soi: http://s-o-i.org/1.1/TAS-10-30-22 Doi: crossef http://dx.doi.org/10.15863/TAS.2015.10.30.22

\section{ЭКОНОМИКА ПРИРОДОПОЛЬЗОВАНИЯ: СИСТЕМА ГОСУДАРСТВЕННОГО УПРАВЛЕНИЯ ОХРАНОЙ АТМОСФЕРНОГО ВОЗДУХА НА РЕГИОНАЛЬНОМ УРОВНЕ}

Аннотация: Главной целью бизнеса является получение прибыли и методы по достижению этой цели, вступают в противоречие с основными ценностями общества. Как следствие - рыночные отношения требуют соответствующего регулирования со стороны государства.

Ключевые слова: рыночные отночения, государственное управление, разрешение на выбросы вредных (загрязняющих) веществ, плата за загрязнение атмосферного воздуха.

Экономическое развитие общества не ставит своей целью разработку идеально сбалансированных эколого-экономических систем. Главной целью бизнеса является получение прибыли и порой методы по её достижению идут в разрез основным ценностям общества. Как следствие - рыночные отношения требуют соответствующего регулирования со стороны государства. Процессы трансформации привели общество к переосмыслению парадигм государственного управления и к переходу цивилизации на постиндустриальные рельсы, на первый план выдвигается её социальная обусловленность. Масштабы государственного управления имеют определенные границы, которые определяются характером объекта управления, естественными правами человека, объективной необходимостью естественного саморегулирования общества, реальными возможностями самого общества, а также уровнем развития системы государственного управления и возможностями государства.[1]

Государственное управление рассматривается как целенаправленное организующее и регулирующее воздействие государства на общественные процессы, отношения и деятельность людей.[2]

Каждый субъект управления должен:

- выражать интересы социальной общности;

- являться системно организованным, со свойственными чертами социальной системы.

В пределах полномочий, установленных законом, субъекты управления применяют различные средства, имеющиеся в их распоряжении: экономические, политические, идеологические. Взаимодействие субъектов управления обеспечивают также и наличие обратных связей. 
Место и роль государственного управления в механизме «разделения труда» определяются следующими характеристиками:

- $\quad$ государственное управление конкретный вид деятельности по осуществлению единой государственной власти, имеющий функциональную и компетенционную специфику, отличающую его от иных видов (форм) реализации государственной власти;

- государственное управление деятельность исполнительно-распорядительного характера. Основным направлением ее является исполнение, т.е. проведение в жизнь законов и подзаконных нормативных актов. Достигается эта цель использованием необходимых юридически-властных полномочий (распорядительство);

- государственное управление прерогатива специальных субъектов, обобщенно обозначаемых как исполнительнораспорядительные органы государственной власти или же органы государственного управления;

- государственное управление исполнительная деятельность, осуществляемая в процессе повседневного и непосредственного руководства хозяйственным, социальнокультурным и административно-политическим строительством;

- государственное управление подзаконная деятельность, осуществляемая «на основе и во исполнение закона», она вторична по отношению к законодательной деятельности [3]

Государственное управление отличает возможность использования всех существующих в обществе разнообразных ресурсов: материальных, интеллектуальных, финансовых, информационных, силовых, демографических и т.д. [4]

Итак, специфику государственного управления обусловливают характер и объем охватываемых этим управлением общественных явлений. Государство, будучи сложным (по элементному составу и связям) и многогранным (по функциям) общественным явлением, придает государственному управлению свойство системности. Только системность может придать ему необходимую согласованность, координацию, целеустремленность, эффективность. [5]

Применительно к современной России в государственном управлении можно отметить переплетение двух противоречивых тенденций. Первая заключается в сокращении директивного начала управления, уменьшении государственного сектора экономики, превращении государства в одного из - хотя и наиболее влиятельного - субъектов

ISPC Innovations in science,

Harrisburg, USA регулирования общественных процессов. Вторая тенденция реализуется в расширении и усложнении задач государства в силу создания рыночной инфраструктуры, формирования новых законодательных и иных нормативно-правовых процедур социальных, экономических и политических отношений, необходимости регулировать становление разных форм собственности и их взаимоотношений. Поэтому нельзя однозначно приветствовать призывы к сокращению объема государственного управления, особенно если он не замещается самоуправленческими механизмами гражданского общества. В таком случае может усилиться состояние неуправляемости, произвола и хаоса, элементы чего в той или иной степени всегда присутствуют в переходном обществе.[6]

В структуре органов государственного управления выделяются три уровня:

- $\quad$ федеральный уровень;

- $\quad$ уровень субъекта;

- $\quad$ муниципальный уровень.

Рассматривая на практике государственную систему управления, авторы выбрали региональный уровень управления охраной атмосферного воздуха и проблемы, возникающие на данном уровне. Министерстве природных ресурсов и экологии Иркутской области (МПР ИО) в своей деятельности руководствуется Положением о Министерстве, утвержденным Постановлением Правительства Иркутской области от 29.12.2009 года № 392/171-пп (в редакции внесённых изменений от 17.12.2014 № 664-пп), структура МПР ИО [7] (рис.1).

Рассматривая конкретные государственные услуги мы остановились на отделе государственной экологической экспертизы разрешительной деятельности, который, исходя из положения о Министерстве, оказывает две государственные услуги:

- выдача разрешений на выбросы вредных (загрязняющих) веществ в атмосферный воздух стационарным источником в соответствии с законодательством;

- организация и проведение государственной экологической экспертизы объектов регионального уровня.

Рассмотрим законодательные нормативы, которые регламентируют необходимость и процедуру получения разрешения на выброс вредных (загрязняющих) веществ в атмосферный воздух от стационарных источников загрязнения (далее разрешение на выброс). Отталкиваясь от ст. 14 Ф3 №96 от 04.05.1999 «Об охране атмосферного воздуха» все хозяйствующие субъекты, имеющие стационарные источники загрязнения атмосферы, должны иметь разрешение на выброс. Постановлением Правительства Российской Федерации № 183 от 
02.03.2000 года установлен порядок выдачи разрешения.

Изучив регламент оказания государственной услуги, утвержденный

Согласно «Правил установления допустимых выбросов вредных веществ промышленными предприятиями» том ПДВ разрабатывается на основе данных инвентаризации промышленного оборудования и утверждается Управлением Роспотребнадзора по Иркутской области в части расчета зоны рассеивания вредных (загрязняющих) веществ, после этого Управление Росприроднадзора по Иркутской области устанавливает нормативы на выброс вредных (загрязняющих) веществ в атмосферный воздух, на основании которых заявитель может получить разрешение.

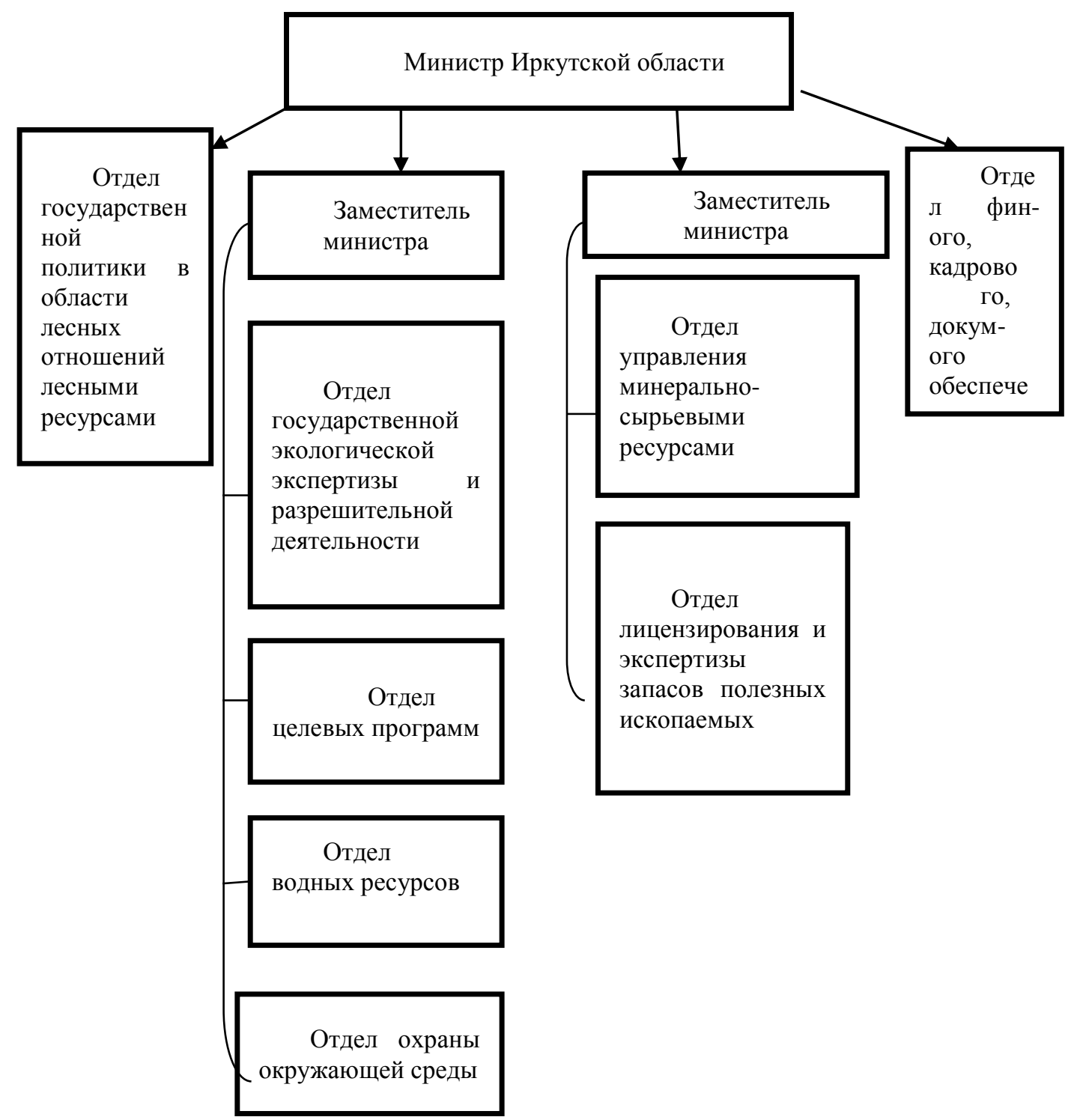

Рисунок 1 - Структура Министерства природных ресурсов и экологии Иркутской области (МПР ИО).

Данный норматив направляется в рамках межведомственного взаимодействия в Министерство природных ресурсов (для предприятий, не подлежащих федеральному государственному экологическому надзору).

Таким образом, данная процедура должная выглядеть так: заявитель проводит инвентаризацию источников загрязнения атмосферы, на основании данных инвентаризации разрабатывается том ПДВ и утверждается в Управлении Роспотребнадзора по ИО (30 дней со дня обращения), после этого том ПДВ утверждается в Управлении Росприроднадзора по Иркутской Области (30 дней со дня обращения), после этого предприятие направляется в Министерство природных

ISPC Innovations in science, 
ресурсов за получением разрешения на выброс (30 дней со дня обращения).

На практике данная процедура начинается с того, что на предприятие, особенно небольшое приходит проверка природоохранной прокуратуры или службы и спрашивает документ, разрешающий негативное воздействие на атмосферный воздух. Малый бизнес, как правило, не имеет в своем штате профессиональных экологов, которые могут пояснить данные законодательные требования и выполнить расчет ПДВ. Стоимость разработки и согласования проекта ПДВ для небольшого предприятия составляет от 50000 руб. до 100000 руб. Кроме того, на практике, предприятия сталкиваются с тем, что сроки осуществления процедур в государственных органах затягиваются и составляют больше 30 дней, установленных регламентом вследствие нехватки исполнителей на рабочих местах.

Штрафных санкций за непредставление расчета платы за негативное воздействие на окружающую среду, а также за его подачу позднее установленного срока не предусмотрено. Однако такие действия могут квалифицироваться как сокрытие экологической информации, ответственность за которое предусмотрена статьей 8.5 Кодекса РФ об административных правонарушениях от 30.12.2001 № 195-Ф3 в виде наложения административного штрафа на должностных лиц в размере от 1000 до 2000 рублей, на юридических лиц - от 10000 до 20000 рублей. В соответствии со статьей 8.41 Кодекса РФ об административных правонарушениях от 30.12.2001 № 195-Ф3 невнесение в установленные сроки платы за негативное воздействие на окружающую среду влечет наложение административного штрафа на должностных лиц в размере от 3000 до 6000 рублей; на юридических лиц - от 50000 до 100 000 рублей.

Кроме того, п. 1 ст. 8.21. КоАП гласит, что выброс вредных веществ в атмосферный воздух или вредное физическое воздействие на него без специального разрешения влечет наложение административного штрафа или административное приостановление деятельности.[9]

Таким образом, мы видим, что неполучение разрешение на выброс ведет, во-первых, к уплате за негативное воздействие в 25-и кратном размере, во-вторых к штрафу до 250 тыс. руб. или к приостановлению деятельности на срок до 90 суток, поэтому для хозяйствующего субъекта получение разрешения является обязательным. Таким образом, в настоящее время для малых предприятий (1-2 производственные площадки) экономически выгоднее заключать договоры на экологическое обслуживание.
Далее авторы считают необходимым рассмотреть законодательные акты, только что вступившие и не вступившие в силу на настоящий момент, но вступающие в силу в будущем. В частности, Ф3-219 от 21.07.2014 и ГОСТ 17.2.3.02-2014. Согласно ГОСТ 17.2.3.0278 проект ПДВ должен пересматриваться каждые пять лет, т.е. разрабатывать проект необходимо один раз в пять лет. Анализируя ГОСТ 17.2.3.022014, который вступил в силу с 01.07.2105, мы видим, что законодательно не прописан «срок годности» проекта ПДВ, что в разрезе ст. 14 ФЗ94 от 01.05.1999 говорит нам о ежегодном пересмотре нормативов ПДВ для предприятий, расположенных на Байкальской природной территории (для Иркутской области от оз. Байкал до г. Черемхово).[10]

Кроме того, Ф3-219 от 21.07.2014 говорит нам об изменении законодательства в области охраны атмосферного воздуха, который вступает в силу с 01.01.2019, в частности о градации предприятий по уровням загрязнения на четыре группы:

- 1-я группа предприятий: объекты, оказывающие значительное негативное воздействие на окружающую среду и относящиеся к областям применения наилучших доступных технологий - обязаны получить комплексное экологическое разрешение (единое разрешение для отходов, сброса, выброса, сроком действия семь лет);

- 2-я группа предприятий: объекты, оказывающие умеренное негативное воздействие на окружающую среду - могут получить комплексное экологическое разрешение, обязаны сдавать ежегодно декларацию о воздействии на окружающую среду;

- 3-я группа предприятий: объекты, оказывающие незначительное негативное воздействие на окружающую среду отчитываются декларативно (о выбросах, отходах и сбросах) в Уполномоченный орган.

- 4-я группа предприятий: объекты, оказывающие минимальное негативное воздействие на окружающую среду - не отчитываются.

Точных критериев градации пока нормативно не установлено, но исходя из опыта, авторы считают, что большинство предприятий будут относиться ко 2 и 3 -ей группам. Также отметим, что для заполнения декларации необходимо иметь уже разработанный том ПДВ, штрафы за непредставление экологической информации и работу без разрешительной документации также планируется увеличить. При таких обстоятельствах предприятию, не зависимо от масштаба, в будущем удобнее будет иметь своего эколога, который будет отслеживать 


\begin{tabular}{|c|c|c|c|c|c|c|}
\hline Impact Factor: & $\begin{array}{l}\text { ISRA (India) } \\
\text { ISI (Dubai, UAF } \\
\text { GIF (Australia) } \\
\text { JIF }\end{array}$ & $\begin{array}{l}=1.344 \\
=\mathbf{0 . 8 2 9} \\
=\mathbf{0 . 3 5 6} \\
=1.500\end{array}$ & $\begin{array}{l}\text { SIS (USA) } \\
\text { PИHЦ (Russia) } \\
\text { ESJI (KZ) } \\
\text { SJIF (Morocco) }\end{array}$ & $\begin{array}{l}=0.912 \\
=0.179 \\
=1.042 \\
=2.031\end{array}$ & ICV (Poland) & $=6.630$ \\
\hline
\end{tabular}

изменения в экологическом законодательстве и в

надлежащем виде оформлять отчетность.

\section{References:}

1. Baxrax DN (2013) Administrativnoe pravo Rossii. Uchebnik dlya vuzov. - M.: Izdatel'stvo NORMA, 2013.

2. Marty'shin OV (2014) Neskol'ko tezisov o perspektivax pravovogo gosudarstva v Rossii. // Gosudarstvo i pravo, 2014, № 6 .

3. Alexin AP, Karmolickij AA (2012) Administrativnoe pravo Rossii. - M.: ZercaloM, 2012.

4. Ovsyanko DM (2013) Administrativnoe pravo: Uchebnoe posobie. - Izd. 3-e, pererab. i dop. — M.: Yurist',2013.

5. Koldin VY (2011) Perspektivy' razvitiya zakonodatel'stva// Vestnik Moskovskogo Universiteta seriya «Pravo» № 6, 2011.

6. Marty'shin OV (2014) Neskol'ko tezisov o perspektivax pravovogo gosudarstva v Rossii. // Gosudarstvo i pravo, 2014, № 6 .

7. (2015) Struktura Ministerstva prirodny'x resursov i e'kologii Irkutskoj oblasti (MPR IO)
Available:

http://irkobl.ru/sites/ecology/about/structure/ (Accessed: 20.10.2015).

8. (2015) Katalog dokumentov informacionnogo banka Irkutskaya oblast' Available: http://sibfo.consultant.ru/irkutsk/list/2015/0710. html (Accessed: 20.10.2015).

9. (2015) Kodeks Rossijskoj Federacii ob administrativny'x pravonarusheniyax (s izmeneniyami na 5 oktyabrya 2015 goda) Available:

http://docs.cntd.ru/document/901807667 (Accessed: 20.10.2015).

10. (2014) Federal'ny'j zakon ot 01.05.1999 №94FZ «O Bajkale» (dejstvuyushhaya redakciya ot 28.06.2014) http://docs.cntd.ru/document/901732256 (Accessed: 20.10.2015). 